\title{
Antioxidant Effects of Xanthohumol and Functional Impact on Hepatic Ischemia-Reperfusion Injury
}

\author{
Andreas Hartkorn, ${ }^{\dagger}$ Florian Hoffmann, ${ }^{\dagger}{ }^{\S}$ Hussam Ajamieh, ${ }^{\S}$ Susanne Vogel, ${ }^{\ddagger}$ Jörg Heilmann, ${ }^{\ddagger}$ Alexander L. Gerbes, ${ }^{\S}$ \\ Angelika M. Vollmar, ${ }^{\dagger}$ and Stefan Zahler*,† \\ Center of Drug Research, Department of Pharmacy, University of Munich, Germany, Klinikum Grosshadern, University of Munich, Germany, \\ and Pharmaceutical Biology, Institute of Pharmacy, University of Regensburg, Germany
}

Received April 14, 2009

\begin{abstract}
Therapeutic effects of dietary flavonoids have been attributed mainly to their antioxidant capacity. Xanthohumol (1), a prominent flavonoid of the hop plant, Humulus lupulus, was investigated for its antioxidant potential and for its effect on NF- $\kappa$ B activation. To examine the biological relevance of $\mathbf{1}$, a hepatic ischemia/reperfusion model was chosen as a widely accepted model of oxidative stress generation. The impact of $\mathbf{1}$ on endogenous antioxidant systems, on the $\mathrm{NF}-\kappa \mathrm{B}$ signal transduction pathway as well as on apoptotic parameters, and on hepatic tissue damage was evaluated. Compound 1 markedly decreased the level of reactive oxygen species in vitro. Furthermore, levels of enzymatic and nonenzymatic antioxidants were restored after pretreatment in postischemic hepatic tissue, and lipid peroxidation was attenuated. NF- $\kappa$ B activity was reduced in vitro as well as in hepatic tissue after ischemia/reperfusion upon pretreatment with 1. In addition, the phosphorylation of Akt was markedly inhibited. Surprisingly, 1 decreased the expression of the antiapoptotic protein $\mathrm{Bcl}-\mathrm{X}$ and increased caspase-3 like-activity, a proapoptotic parameter. Moreover, hepatic tissue damage as well as TNF- $\alpha$ levels increased in xanthohumol-pretreated liver tissue after ischemia/reperfusion. In summary, xanthohumol did not protect against ischemia/reperfusion injury in rat liver, despite its antioxidant and NF- $\kappa$ B inhibitory properties.
\end{abstract}

Several dietary polyphenols, which are mainly found in fruits, vegetables, tea, grains, and legumes, have gained interest due to their health benefits and their protective effects in different human disease models. ${ }^{1-3}$ Flavonoids are the most widely distributed group of plant polyphenolics. Their beneficial effect is attributed primarily to their role as antioxidants, which is assumed to be associated with their polyphenolic structure, enabling them to chelate metal ions and to scavenge singlet oxygen as well as reactive oxygen species (ROS). ${ }^{4,5}$ The latter are implicated in direct injury to cells as well as in the generation of various acute-phase proteins and in the activation of redox-sensitive transcription factors when the endogenous redox degrading system is overstressed. ${ }^{6}$ Importantly, treatment with flavonoids reduces ROS-mediated cellular alterations and prevents oxidative tissue injuries. ${ }^{7,8}$

Xanthohumol (1) is the principal prenylated flavonoid of the hop plant (Humulus lupulus L.; Cannabaceae), which constitutes approximately $82-89 \%$ of the total amount of prenylated flavonoids of different hop varieties. ${ }^{9}$ The only dietary source of $\mathbf{1}$ is beer, since hops are added for bitterness and the typical aroma. In recent years, $\mathbf{1}$ has attracted considerable interest, as it was identified as a broad-spectrum anticancer and chemopreventive compound, which is assumed to be in particular due to its diverse antioxidant and free-radical-scavenging properties. ${ }^{10-13}$<smiles>COc1cc(O)c(CC=C(C)C)c(O)c1C(=O)/C=C/c1ccc(O)cc1</smiles>

However, ROS are assumed to play an important role in various pathological conditions apart from cancer, such as the ischemia/

* To whom correspondence should be addressed. Tel: +49-89-218077196. Fax: +49-89-2180-77170. E-mail: Stefan.Zahler@cup.unimuenchen.de.

Department of Pharmacy, University of Munich.

$\S$ Klinikum Grosshadern, University of Munich.

$\doteqdot$ Institute of Pharmacy, University of Regensburg. reperfusion injury (IRI) of the liver. ${ }^{14}$ Hepatic IRI contributes to the morbidity and mortality associated with shock, transplantation, and liver surgery. ${ }^{15,16}$ It has been generally accepted as a system for oxidative stress in vivo. ${ }^{17}$ Therapeutic interventions by treatment with antioxidants or gene therapy using viral and nonviral vectors containing genes of endogenous antioxidants have been shown to improve hepatic tissue injury. ${ }^{18,19}$ Along with ROS, the redoxsensitive transcription factor nuclear factor $\kappa \mathrm{B}(\mathrm{NF}-\kappa \mathrm{B})$ has been reported to play a pivotal role in the ischemia/reperfusion (IR) model, leading to the expression of proinflammatory cytokines and cell adhesion molecules, resulting in neutrophil-mediated inflammation following tissue injury. ${ }^{15,20,21}$ Interestingly, NF- $\kappa \mathrm{B}$ inhibition was attributed to antioxidant and radical-scavenging approaches and has been claimed to reduce injury following hepatic IR. ${ }^{19,22,23}$ Thus, an interdependency of oxidative stress and NF- $\kappa$ B activation with tissue injury in hepatic IR is generally accepted. ${ }^{18,24,25}$

These data have prompted us to elucidate the role of $\mathbf{1}$ in a complex oxidative stress driven injury model. The aim of this study was to investigate the impact of the dietary flavonoid xanthohumol on the hepatic IRI and to understand the underlying molecular mechanisms.

\section{Results and Discussion}

Impact of Xanthohumol (1) on ROS Production in a CellFree (Xanthine/Xanthine Oxidase) and a Cellular System ( H$_{2}$ FDA). Structure-activity relationship studies of flavonoids have shown that their antioxidant activities are attributed mainly to certain hydroxy substituents in the A- and B-rings and the 2,3-double bond conjugated with the 4-oxo function. ${ }^{4}$ Flavonoid 1 displays these structural specificities, and, indeed, the high antioxidant potential of this compound was recently published in vitro. ${ }^{12,13}$ The ability of compound $\mathbf{1}$ to scavenge superoxide radical was evaluated by chemiluminescence measurement using a xanthine/xanthine oxidase assay. Compound 1 (Figure 1A,B) showed a dose-dependent reduction in ROS production with an $\mathrm{IC}_{50}$ of $15 \mu \mathrm{M}$. Intracellular response to oxidative challenge $\left(\mathrm{H}_{2} \mathrm{O}_{2}\right)$ was measured by loading HEK 293 cells with $20 \mu \mathrm{M}$ dihydrofluorescein diacetate $\left(\mathrm{H}_{2} \mathrm{FDA}\right)$. After penetrating the cell membrane, ester groups of $\mathrm{H}_{2} \mathrm{FDA}$ are 

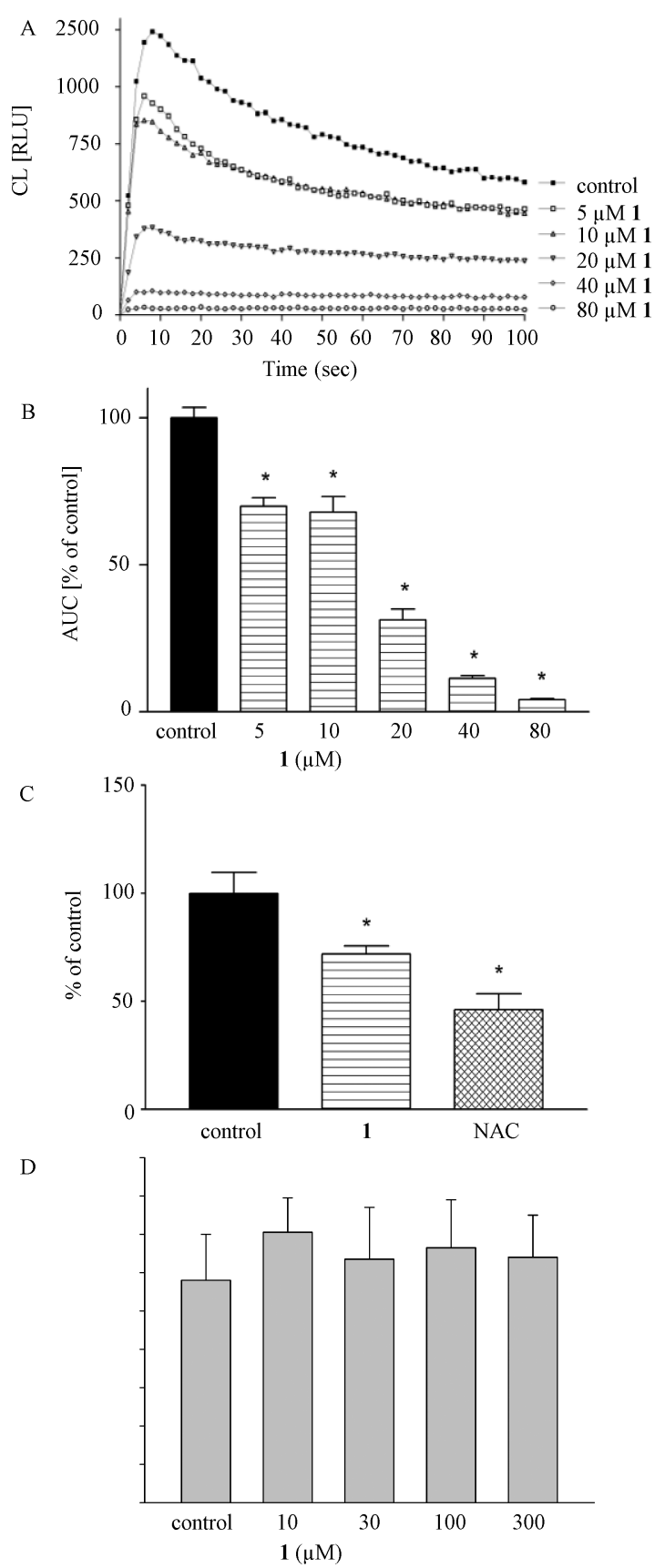

Figure 1. Antioxidant activity of xanthohumol (1) in a cell-free and in a cellular system. (A) Time course of ROS inhibition in a cell-free xanthine/xanthine-oxidase model depending on different concentrations of $\mathbf{1}$ in comparison to the control. (B) Area under the curve (AUC) of light emission from chemiluminescent reaction for different concentrations of $\mathbf{1}$ in comparison to controls (100\%), in a cell-free xanthine/xanthine-oxidase model. Data are presented as mean $\pm \operatorname{SEM}\left(n=9,{ }^{*} p<0.05\right.$ vs control, Student's $t$ test). (C) Fluorescence was measured in $\mathrm{H}_{2}$ FDA loaded HEK 293 cells pretreated with $40 \mu \mathrm{M} \mathrm{XN}$ prior to stimulation with $\mathrm{H}_{2} \mathrm{O}_{2}$. Significance was calculated at a $95 \%$ concentration interval in comparison to the corresponding controls $(*)$. Data are presented as mean $\pm \operatorname{SEM}(n=4, * p<0.05$ vs control, Student's $t$ test $)$. The antioxidant $N$-acetylcysteine (NAC) was used as positive control. (D) Cytotoxicity of $\mathbf{1}$ was measured after incubation with 10 to $300 \mu \mathrm{M}$ for $3 \mathrm{~h}$ by the MTT assay in HEK 293 cells. No cytotoxicity was found for any concentration tested.

cleaved by esterases, which leads to the formation of dihydrofluorescein, a ROS-sensitive fluorescence dye. A $40 \mu \mathrm{M}$ concentration of $\mathbf{1}$ (Figure 1C) showed significant fluorescence reduction (to 71.9 $\pm 9.2 \%$ ), in comparison to the corresponding control. Treatment with the well-established antioxidant $N$-acetylcysteine (NAC; 1 $\mathrm{mM}$ ), which served as positive control, attenuated fluorescence to $46.2 \pm 14.9 \%$. The MTT test with HEK 293 cells showed that $\mathbf{1}$ is not cytotoxic up to concentrations of $300 \mu \mathrm{M}$ (Figure 1D). Therefore, the reduction of ROS production in the cellular assay cannot be attributed to cytotoxicity.

Antioxidant Parameters and Indicators of Oxidative Stress in Hepatic Tissue Pretreated with Xanthohumol (1) Prior to Ischemia and Reperfusion. Since antioxidant activity has been found to be, at least in part, responsible for the broad-spectrum anticancer and chemopreventive properties of $\mathbf{1}$, we were interested in evaluating the potential of xanthohumol in another pathophysiological system, which is driven by oxidative stress such as the hepatic ischemia and reperfusion. Treatment with the flavonoid rutin in hepatic ischemia/reperfusion injury has already been demonstrated to be beneficial in preventing oxidative damage, hence reducing liver tissue injury. ${ }^{26}$ Similar studies have confirmed these results for resveratrol, epigallocatechin gallate, quercetin, and anthocyanins, respectively. ${ }^{7,27-29}$ In our study, IR leads to significant reductions of enzymatic activity of SOD in liver tissue. This effect is abolished after administration of $2.26 \mathrm{mM} 1$ (Figure 2A). Thus, we show herein for the first time that xanthohumol (1) is able to restore the endogenous ROS scavenging enzyme superoxide dismutase (SOD) in IRI. SOD accounts for detoxification of a major proportion of the highly reactive superoxide anion radical in the liver tissue, and the administration of SOD derivatives in the hepatic IR process has been demonstrated previously to be protective. ${ }^{30}$ We demonstrate that the activity of the nonenzymatic redoxdegrading antioxidant GSH was reduced significantly in animals subjected to IR, but kept unchanged by xanthohumol $(2.26 \mathrm{mM})$ treatment (Figure 2B). Again, exogenous administration of the nonenzymatic antioxidant GSH in different IR models has been shown to have beneficial effects regarding hepatic tissue injury. ${ }^{15,31}$ Consequently, we determined lipid peroxidation as a marker for oxidative stress by quantifying the 8-isoprostane content. An increase in the 8-isoprostane levels was observed in animals subjected to IR. This effect was decreased significantly after treatment with $1(2.26 \mathrm{mM})$ prior to IR (Figure 2C). Thus, xanthohumol has a strong antioxidant potential in the complex hepatic IR model.

Effect of Xanthohumol (1) on NF- $\kappa$ B Activity in Vitro (Reporter Gene Assay) and in Vivo (EMSA). Along with ROS, the redox-sensitive transcription factor NF- $\kappa$ B has been shown to be relevant for hepatic IRI, as it up-regulates the expression of different proinflammatory genes and correlates with the severity of tissue damage. ${ }^{21,32}$ Treatment of rats prior to IRI with green tea extract, which contains high levels of polyphenols, has been shown to inhibit NF- $\kappa \mathrm{B}$ binding activity in this model. ${ }^{23}$ Here, we demonstrate dose-dependent inhibitory effects of $\mathbf{1}\left(\mathrm{IC}_{50} 35 \mu \mathrm{M}\right)$ in a TNF- $\alpha$-induced NF- $\kappa \mathrm{B}$-dependent reporter-gene assay (Figure $3 \mathrm{~A})$. PDTC served as a well-established inhibitor of NF- $\kappa \mathrm{B}$ activity.

To investigate the impact of $\mathbf{1}$ on NF- $\kappa$ B DNA-binding activity in the liver after IR, the electrophoretic mobility shift assay (EMSA) was performed with nuclear extracts of respective tissue samples. As shown in Figure $3 \mathrm{~B}, \mathrm{NF}-\kappa \mathrm{B}$ activity of the liver tissue increased greatly after $6 \mathrm{~h}$ of cold ischemia followed by reperfusion of 150 min when compared to untreated liver tissue. Animals treated with $2.26 \mathrm{mM} 1$ prior to the ischemic period revealed attenuated DNA binding activity of NF- $\kappa \mathrm{B}$.

Impact of Xanthohumol (1) on Expression of Phosphorylated Akt in Rat Liver after IR. The Akt pathway is an important upstream activator of the NF- $\kappa$ B pathway and has been described previously to be repressed by $1 .{ }^{9}$ Interestingly, inhibition of Akt phosphorylation was achieved by pretreatment with $\mathbf{1}$ in the liver as well. These results suggest that NF- $\kappa$ B inhibition by $\mathbf{1}$ in cold IR might be, at least in part, regulated by an Akt inhibition. 

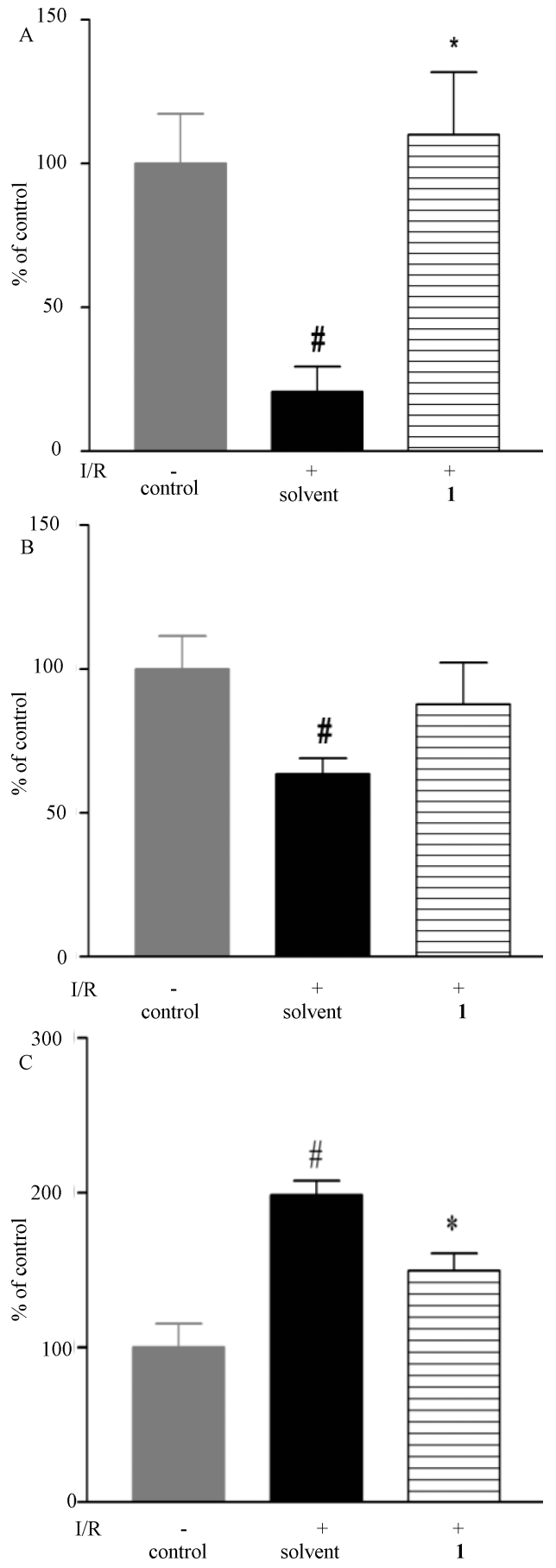

Figure 2. Effect of xanthohumol (1) on oxidative defense and stress parameters in IR-treated hepatic tissue. (A) SOD activity after treatment with $2.26 \mathrm{mM} 1$ or solvent, respectively, prior to IR. Livers of untreated animals served as control (100\%). Data are presented as mean $\pm \operatorname{SEM}(n=3, \# p<0.05$ vs control, $* p<0.05$ vs solvent, Student's $t$ test). (B) GSH level after treatment with $2.26 \mathrm{mM} 1$ or solvent, respectively, of livers subjected to IR. Livers of untreated animals served as control (100\%). Data represent means \pm SEM of triplicates, containing three animals per group (\# $p<$ 0.05 vs control, Student's $t$ test). (C) 8-Isoprostane level after treatment with $2.26 \mathrm{mM} 1$ or solvent, respectively, of livers subjected to IR. Livers of untreated animals served as control $(100 \%)$. Data are presented as mean $\pm \operatorname{SEM}(n=3, \# p<0.05$ vs control, ${ }^{*} p<0.05$ vs solvent, Student's $t$ test).

It has been shown that phosphorylation of Thr-308 is the main activating event of Akt, although phosphorylation of both domains (Thr-308 and Ser-473) might be necessary for full activation of
Akt. $^{33}$ Xanthohumol (1) $(2.26 \mathrm{mM})$ pretreatment abrogated the phosphorylation of both Ser-473 and Thr-308, respectively, in comparison to solvent-treated animals after IR (Figure 3C). The quantitative densitometric analysis of both phosphorylation sites showed no effects of ischemia and reperfusion per se, but underlines the inhibition of both types of phosphorylation by 1 (Figure 3D).

Effect of Xanthohumol (1) on Expression of Antiapoptotic Proteins and on Caspase Activity in Rat Liver after IR. Akt is described as a typical antiapoptotic kinase involved in IRI, ${ }^{33}$ as it inactivates proapoptotic proteins such as Bad and subsequently activates antiapoptotic proteins of the Bcl-2 family. ${ }^{33}$ Since we have described previously an antiapoptotic action of Akt in the liver, ${ }^{21}$ and since Akt has been described to induce an antiapoptotic pattern of proteins of the Bcl-2 family, ${ }^{34}$ we took a closer look at antiand proapoptotic proteins in this context. The proteins of the Bcl-2 family exert either pro- or antiapoptotic effects. Bcl-xl is one of the antiapoptotic proteins in this family. ${ }^{35}$ Pretreatment with $1(2.26$ $\mathrm{mM}$ ) reduced the protein level of Bcl-xl in livers subjected to IR (Figure 4A). Thus, we could demonstrate that 1-mediated Akt inhibition correlates with down-regulation of the levels of the antiapoptotic protein Bcl-xl. This is well in accordance with previous findings with xanthohumol in nonhepatic cells. ${ }^{36,37}$

Caspases are intracellular cysteine proteases that mediate inflammation and cell death. Caspase-3 in particular is the main effector molecule of apoptosis and a selective inhibitor in the IR process that effectively reduces hepatic IRI. ${ }^{38}$ Intrahepatic caspase-3-like activity was measured after IR, as caspase-3 activation plays a pivotal role in tissue damage. The hepatic caspase activity in IRtreated animals was significantly increased in comparison to nonischemic animals. Interestingly, $1(2.26 \mathrm{mM})$-treated animals showed a significant increase in hepatic caspase activity (Figure 4B).

Impact of Xanthohumol (1) on Liver Injury. The perfusates were collected during the reperfusion period, and liver enzymes $(\mathrm{AST}+\mathrm{ALT})$, a parameter for hepatocyte damage, as well as LDH (a more general indicator of cytotoxicity) were measured. Pretreatment with 1 showed a tendency toward increased AST and ALT activity during late reperfusion in perfusate compared to solventtreated animals after IR (Figures 5A,B). Thus, surprisingly, hepatic tissue damage was not improved by pretreatment with $\mathbf{1}$, despite its antioxidant and $\mathrm{NF}-\kappa \mathrm{B}$ inhibitory activities. Instead, hepatic tissue injury was slightly increased, as also shown by increased levels of LDH (Figure 5C). Since these effects are only significant at $150 \mathrm{~min}$ of reperfusion, an acute and direct cytotoxic effect of the relatively high concentrations of $\mathbf{1}$ during ischemia can be excluded. The levels of TNF- $\alpha$ (a cytokine that is partly regulated by $\mathrm{NF}-\kappa \mathrm{B}$ ) in the perfusates show an increase over time, but are not significantly influenced by $\mathbf{1}$ (Figure 5D).

These results were unexpected, as antioxidant activities of flavonoids and general $\mathrm{NF}-\kappa \mathrm{B}$ inhibition are assumed to be protective in several oxidative stress driven diseases and, in particular, hepatic IRI. To this end, the role of NF- $\kappa$ B and Akt in IR of the liver has to be examined carefully, requiring a detailed interpretation of the data obtained. First, the inhibition of the protein kinase Akt must be interpreted critically regarding these contrary results. Apart from its activation of NF- $\kappa \mathrm{B}$, Akt regulates cell survival, cell cycle, and proliferation. ${ }^{39}$ Interestingly, constitutively active Akt has been shown to be beneficial during hepatic IR, although long-term Akt activation has potential deleterious effects as well. ${ }^{40}$ Moreover, our research group has demonstrated that preconditioning with $\alpha$-lipoic acid induces temporary Akt phosphorylation and in turn reduces tissue injury after IR. ${ }^{21}$ Thus, general Akt inhibition as presented here might have a harmful potential following IR. Second, the role of NF- $\kappa$ B in the liver has to be carefully examined during IRI. It has been assumed that NF$\kappa \mathrm{B}$ in the liver displays an ambiguous role, depending on the cell type addressed. NF- $\kappa$ B activation in hepatocytes is essential for 


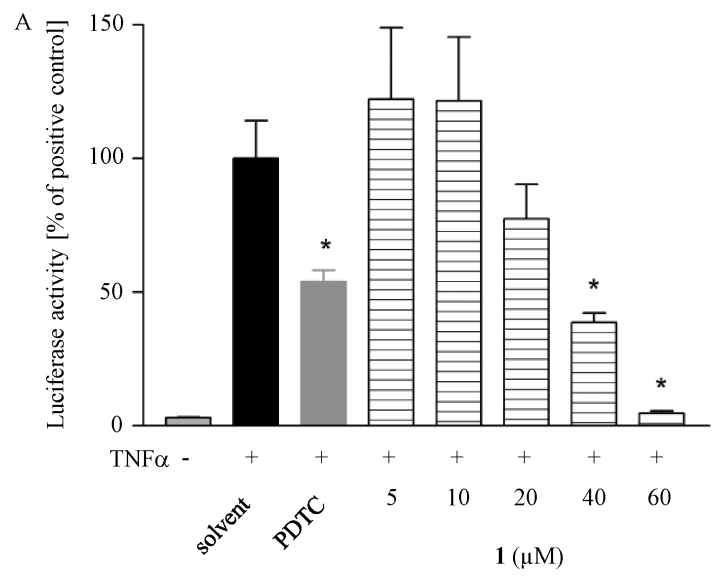

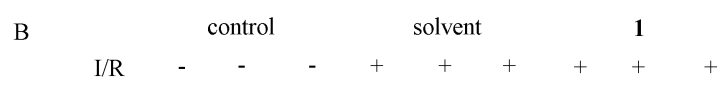
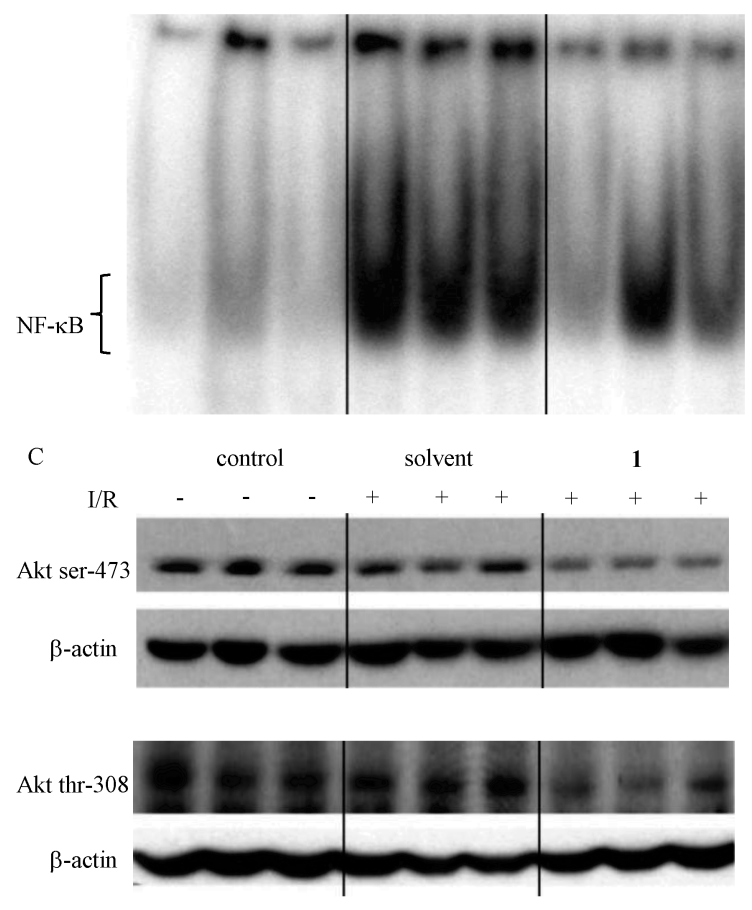

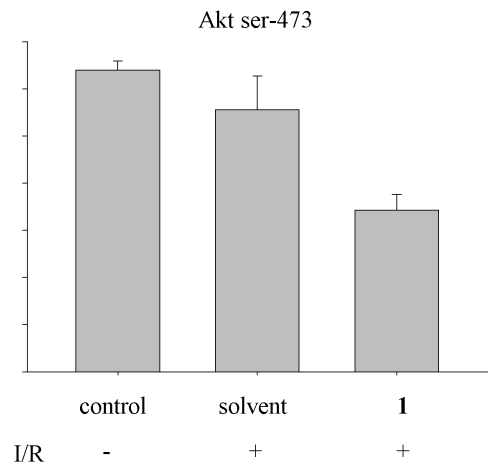

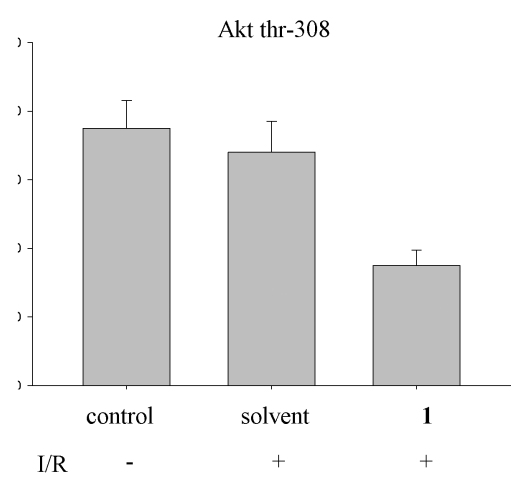

Figure 3. Impact of xanthohumol (1) on the NF- $\kappa$ B signal transduction pathway. (A) NF- $\kappa$ B promoter activity of HEK 293 cells treated with different concentrations of 1 prior to TNF- $\alpha$ stimulation. NF- $\kappa$ B activity of cells treated with solvent were set at $100 \%$, and PDTC-treated cells were used as a positive control. Data are presented as mean \pm SEM $(n=3$, * $p<0.05$ vs control, Student's $t$ test). (B) NF- $\kappa$ B binding activity was determined in liver tissue by EMSA. Liver homogenates were treated with $2.26 \mathrm{mM} \mathbf{1}$ or solvent, respectively, prior to IR. Liver tissue of untreated animals served as control. One representative gel shift experiment is shown $(n=3)$. (C) Hepatic protein levels of phosphorylated Akt (Ser-473, upper panel; Thr-308, lower panel) and $\beta$-actin by WB analysis of livers treated with $2.26 \mathrm{mM} 1$ or solvent, respectively, prior to IR. Liver tissue of untreated animals served as control. One representative blot is shown $(n=3)$. (D) Quantitative densitometric evaluation of phosphorylated Akt (Ser-473, left; Thr-308, right panel), depicted in part $\mathrm{C}(n=3)$. 


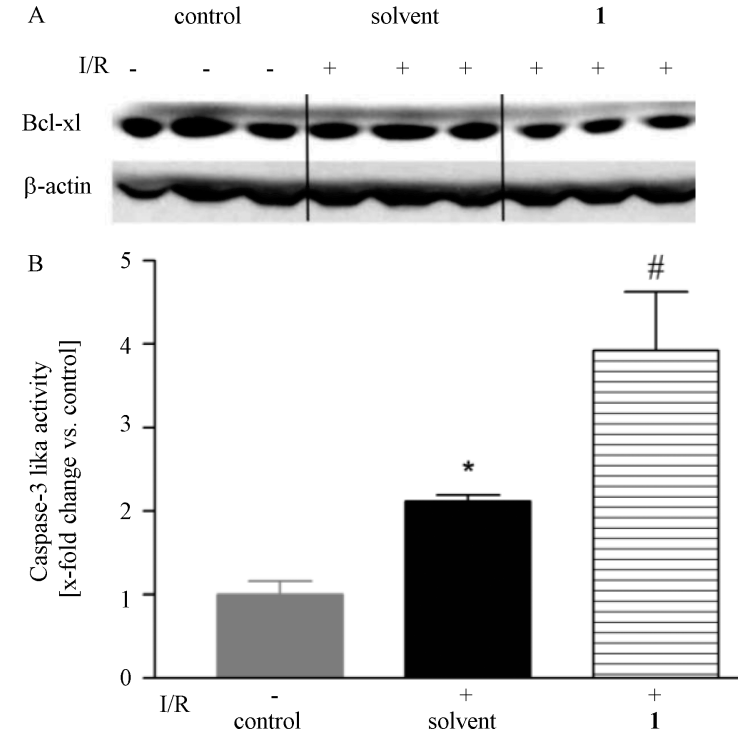

Figure 4. Influence of xanthohumol (1) on anti- and proapoptotic parameters. (A) Hepatic Bcl-xl expression by western blot analysis of livers treated with $2.26 \mathrm{mM} 1$ or solvent, respectively, prior to IR. $\beta$-Actin expression served as loading control. Liver tissue of untreated animals served as control. One representative blot is shown $(n=3)$. (B) Caspase-3-like activity of animals treated with $2.26 \mathrm{mM} 1$ or solvent, respectively, prior to IR. Caspase activity of liver tissue of untreated animals (control) was set as 1 . Data are presented as mean $\pm \operatorname{SEM}\left(n=3,{ }^{*} p<0.05\right.$ vs control, Student's $t$ test).

hepatocyte regeneration, as it exerts antiapoptotic properties. ${ }^{41}$ In contrast, the resident liver macrophages, the Kupffer cells, are presumed to be largely responsible for the excessive inflammatory response induced by IRI. ${ }^{15,20}$ Therefore, a selective inhibition of $\mathrm{NF}-\kappa \mathrm{B}$ in the Kupffer cells may be a more promising approach. ${ }^{41,42}$ Since it is unlikely that $\mathbf{1}$ inhibits NF- $\kappa \mathrm{B}$ selectively in Kupffer cells, a cell-type-independent and predominant NF- $\kappa \mathrm{B}$ inhibition in hepatocytes by xanthohumol might not result in hepatic tissue protection, despite its antioxidant properties.

In conclusion, these results indicate that the flavonoid xanthohumol (1) from $H$. lupulus does not improve tissue injury after hepatic ischemia and reperfusion despite its extensive antioxidant activities. Thus, antioxidative properties of natural polyphenols do not necessarily warrant beneficial therapeutic usage. To this end, the complexity of oxidative stress-driven signaling pathways in various organ and disease systems has to be taken into account.

\section{Experimental Section}

Synthesis of Xanthohumol (1). Compound $\mathbf{1}$ was synthesized in pure form as recently described. ${ }^{43}$

Cell-Free System. Xanthine/Xanthine-Oxidase Assay. The chemiluminescence mixture was prepared immediately before analysis by mixing $230 \mu \mathrm{L}$ of $1 \mathrm{mM}$ xanthine (Sigma Aldrich, Steinheim, Germany) and $30 \mu \mathrm{L}$ of a solution containing solvent (control) or different concentrations of $1(5-80 \mu \mathrm{M})$, respectively. To start the reaction, 20 $\mu \mathrm{L}$ of $1 \mathrm{mM}$ luminol (Sigma Aldrich) and $20 \mu \mathrm{L}$ of $0.5 \mathrm{U} / \mathrm{mL}$ xanthineoxidase (Sigma Aldrich) were injected into the mixture. Chemiluminescence was measured for $100 \mathrm{~s}$ at $37^{\circ} \mathrm{C}$ using an Orion II microplate luminometer (Berthold Detection Systems, Pforzheim, Germany), and the results were expressed as relative light units (RLU) or its area under the curve (AUC).

Cell Culture. Cell Line. The human embryonic kidney cell line 293 (HEK 293; DSMZ-German collection of microorganisms and cell cultures, ACC 305) was grown in phenol-red-free DMEM (PAA Laboratories, Pasching, Austria), supplemented with $10 \%$ fetal calf serum (Biochrom KG, Berlin, Germany) and $2 \mathrm{mM}$ glutamine (Merck, Darmstadt, Germany) at $37{ }^{\circ} \mathrm{C}$ and $5 \% \mathrm{CO}_{2}$ in $75 \mathrm{~cm}^{2}$ tissue culture flasks. Cells were split when reaching ca. $85-90 \%$ confluency. Cells were washed with phosphate-buffered saline (PBS) and subsequently detached with $0.05 \%$ trypsin $/ 0.02 \%$ EDTA in PBS.

Dihydrofluorescein Diacetate Assay. Cells were seeded in 24-well plates and when reaching about $85-90 \%$ confluency, treated for $2 \mathrm{~h}$ with $1(40 \mu \mathrm{M})$ or $N$-acetylcysteine (NAC, $1 \mathrm{mM})$, respectively. After $90 \mathrm{~min}$, the cells were loaded additionally with $20 \mu \mathrm{M}$ dihydrofluorescein diacetate (Invitrogen, Karlsruhe, Germany) by incubation for $30 \mathrm{~min}$ at $37{ }^{\circ} \mathrm{C}$ in the dark. Subsequently, cells were washed and stimulated with $1 \mathrm{mM} \mathrm{H}_{2} \mathrm{O}_{2}$ for 20 min. Fluorescence was measured with a SpectraFluor Plus microplate reader (Tecan, Crailsheim, Germany), using an excitation and emission wavelength of 485 and $535 \mathrm{~nm}$, respectively.

MTT Assay. Cells were seeded in 24-well plates and when reaching about $85-90 \%$ confluency, treated for $3 \mathrm{~h}$ with 1 at concentrations from 10 to $300 \mu \mathrm{M}$. Then, $10 \mu \mathrm{L}$ of a $5 \mathrm{mg} / \mathrm{mL}$ solution of MTT reagent was added, and the mixture was incubated for $1 \mathrm{~h}$ at $37^{\circ} \mathrm{C}$. The blue precipitate was solubilized with DMSO, and absorption was measured at $550 \mathrm{~nm}$.

NF- $\kappa$ B Reporter Gene Assay. HEK 293 cells were seeded at a concentration of $4 \times 10^{6}$ cells $/ 100 \mathrm{~mm}$ dish. The next day, cells were transiently transfected with a plasmid containing a promoter with repetitive $\mathrm{NF}-\kappa \mathrm{B}$ binding sites driving a firefly luciferase gene using the $\mathrm{Ca}^{2+}$-phosphate method (p NF- $\kappa \mathrm{B}$ luc plasmid, Stratagene, Heidelberg, Germany). Transfected cells were seeded in 24-well plates at a concentration of $1 \times 10^{5}$ cells/well and grown for an additional $16 \mathrm{~h}$. Then cells were preincubated for $2 \mathrm{~h}$ with different concentrations of $1(5,10,20,40$, and $60 \mu \mathrm{M})$ and subsequently stimulated with $1 \mathrm{ng} /$ $\mathrm{mL}$ TNF- $\alpha$ (Calbiochem, San Diego, CA) for $6 \mathrm{~h}$. Pyrrolidine dithiocarbamate (PDTC, $50 \mu \mathrm{M}$; Sigma Aldrich)-preincubated cells served as a positive control. Finally, cells were washed with PBS and lysed, and the NF- $\kappa \mathrm{B}$ activity was measured with a commercial luciferase assay kit (Luciferase Assay System; Promega, Mannheim, Germany), according to the manufacturer's instructions, using a luminometer (AutoLumatPlus, Berthold Technologies, Bad Wildbad, Germany).

Isolated Liver Perfusion Model. Animals. Male Sprague-Dawley rats (6 weeks old), weighing 200-240 g, were purchased from Charles River Laboratories (Sulzfeld, Germany) and housed in a climatized room with a $12 \mathrm{~h}$ light-dark cycle. The animals had free access to chow (Ssniff, Soest, Germany) and tap water up to the time of the experiments. All animals received humane care in compliance with the Principles of Laboratory Animal Care. This study was registered with the local animal welfare committee.

Cold Ischemia and Reperfusion. After opening the abdomen by a midline laparotomy, the bile duct, portal vein, and suprahepatic inferior vena cava were cannulated. The livers were drained and rinsed free from blood in situ with hemoglobin-free and albumin-free bicarbonate-

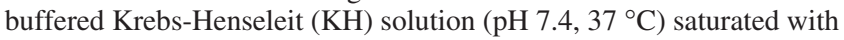
$95 \% \mathrm{O}_{2}$ and $5 \% \mathrm{CO}_{2}$. Additionally, the hepatic artery, the infrahepatic inferior vena cava, and the right kidney vein were ligated. The perfusion medium was pumped constantly through the liver with a peristaltic pump (Digi-staltic, Masterflex, Gelsenkirchen, Germany) in a nonrecirculating fashion $(30 \mathrm{~mL} / \mathrm{min})$. After $30 \mathrm{~min}$ of perfusion, livers were flushed with $100 \mathrm{~mL}$ of ice-cold $\left(4{ }^{\circ} \mathrm{C}\right)$ PBS solution, initiating the cold ischemic period. After stopping the perfusion, organs were preserved at $4{ }^{\circ} \mathrm{C}$ for $6 \mathrm{~h}$. Following the period of ischemia, livers were reperfused with $\mathrm{KH}$ buffer for $150 \mathrm{~min}$ at $37^{\circ} \mathrm{C}$ with a flow rate of $3.0-3.5 \mathrm{~mL} \times \mathrm{min}^{-1} \times \mathrm{g}$ liver. Perfusate samples were collected and kept at $-80{ }^{\circ} \mathrm{C}$ for transaminase and LDH measurement. Liver samples were obtained at the end of the reperfusion period and were snap-frozen in liquid nitrogen until analysis.

Treatment Protocols. For treatment of livers, $2.26 \mathrm{mM} 1$ was dissolved in the dissolution medium (4\% propylene glycol, 3\% TWEEN 80 in PBS) and filled in NORM-JECT syringes (Henke Sass Wolf, Tuttlingen, Germany). The chilled solutions $\left(4^{\circ} \mathrm{C}\right)$ were injected into the portal vein right before the ischemic period. Injection of the solution medium served as a control. This treatment with a high concentration of $\mathbf{1}$ during cold ischemia served to simulate the conditions during organ preservation for transplantation. The rapid washout during reperfusion makes this high concentration necessary in order to keep up effective levels of 1 (approximately in the $\mu \mathrm{M}$ range) in the first minutes of reperfusion.

Glutathione Measurement. Glutathione (GSH) was measured using the colorimetric microplate assay from Oxford Biomedical Research (Oxford, MI). Briefly, the total GSH content of the liver tissue 

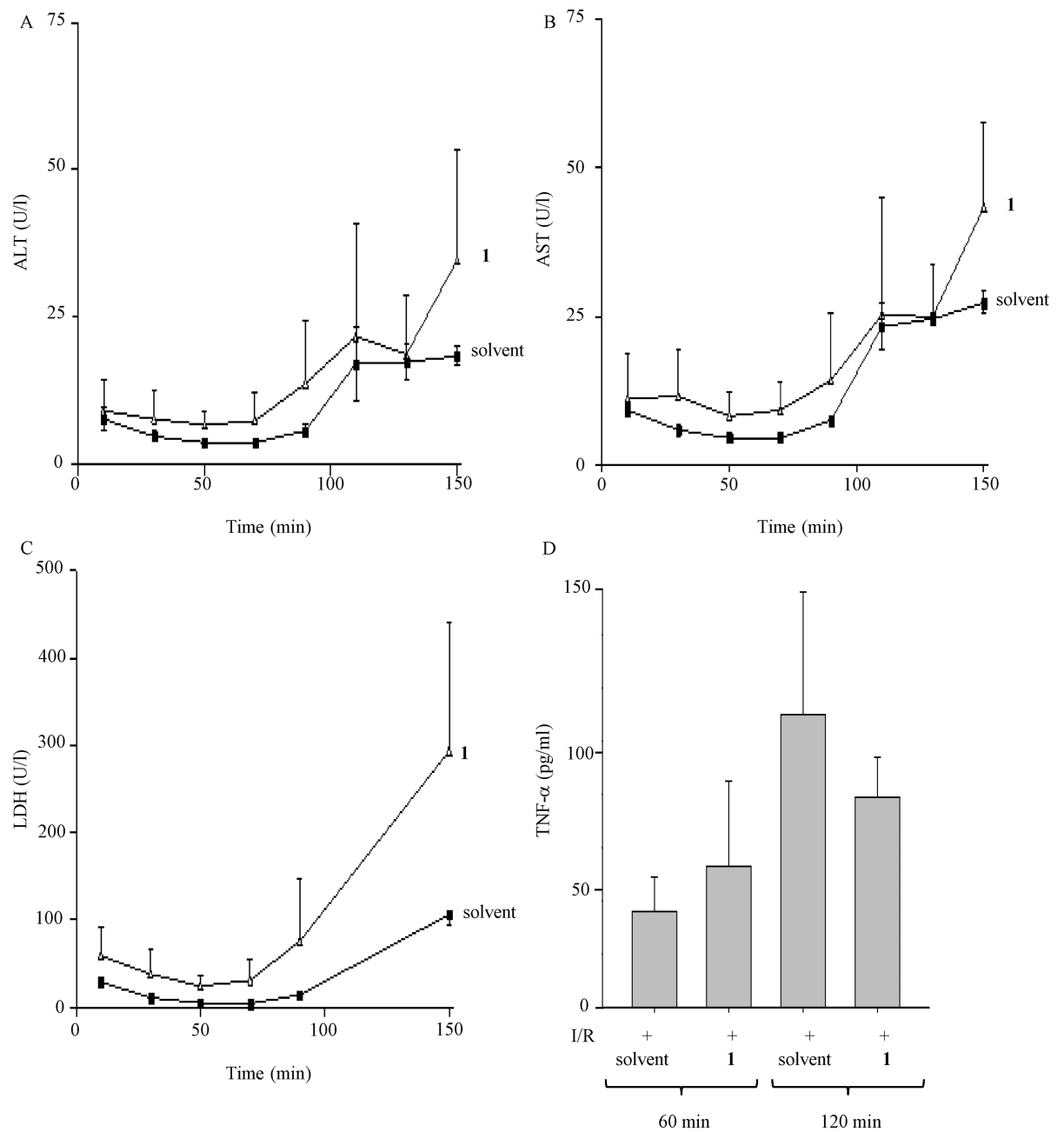

Figure 5. Impact of xanthohumol (1) on liver tissue injury parameters and proinflammatory cytokine level. (A) Time course of ALT levels of liver perfusates treated with $2.26 \mathrm{mM} 1$ or solvent, respectively, prior to IR. Data are presented as mean \pm SEM ( $n=3$ ). (B) Time course of AST levels of liver perfusates treated with $2.26 \mathrm{mM} 1$ or solvent, respectively, prior to IR. Data are presented as mean \pm SEM $(n=3)$. (C) Time course of LDH levels of liver perfusates treated with $2.26 \mathrm{mM} 1$ or solvent, respectively, prior to IR. Data are presented as mean \pm SEM $(n=3)$. (D) TNF- $\alpha$ levels of liver perfusates were determined by ELISA, of 1 (2.26 mM) or solvent-treated animals, respectively, after 60 and 120 min reperfusion. Data are presented as mean $\pm \operatorname{SEM}(n=3)$.

homogenate is measured after reduction of DTNB [5,5'-dithiobis(2nitrobenzoic acid)], causing a colored ion that absorbs light at $405 \mathrm{~nm}$. The absorption is proportional to the total GSH concentration. The results were expressed as percentage of untreated controls. Protein content was determined using the Bradford method. ${ }^{44}$

Superoxide Dismutase Activity Assay. Superoxide dismutase (SOD) activity was analyzed using the pyrogallol method described by Marklund and co-workers. ${ }^{45}$ The amount of enzyme that inhibits the autoxidation rate of pyrogallol by $50 \%$ was defined as one unit. The results are expressed as percentage of untreated controls. Protein content was determined using the Bradford method. ${ }^{44}$

Lipid Peroxidation. The 8-isoprostane concentration of liver homogenates was measured using the 8-isoprostane EIA Kit from Cayman Chemicals (Ann Arbor, MI). Briefly, the assay is based on the competitionbetween 8-isoprostaneandan 8-isoprostane-acetylcholinesterase conjugate. After addition of the substrate, the product of this enzymatic reaction has a distinct yellow color and absorbs at $412 \mathrm{~nm}$. The absorption is indirectly proportional to the total 8-isoprostane content. The results were expressed as percentage of untreated controls.

NF- $k$ B Electrophoretic Mobility Shift Assay. Electrophoretic mobility shift assays (EMSA) were performed as described previously by our group. ${ }^{21}$ The consensus binding sequence used for NF- $\kappa$ B was 5'-AGT TGA GGG GAC TTT CCC AGG C-3' (Promega, Mannheim, Germany). Relative light unit (RLU) density was determined by autoradiography using the Cyclone Phosphor Imager (Perkin-Elmer, Dreieich, Germany).
Western Blot Analysis. Western blot analysis was performed as described previously. ${ }^{21}$ Proteins transferred to the membrane were identified by incubating at $4{ }^{\circ} \mathrm{C}$ overnight with primary antibodies against Bcl-xl (Santa Cruz, Heidelberg, Germany) and phosphorylated Akt (Ser 473 and Thr 308; Cell Signaling, Danvers, MA), followed by incubation with a HRP-conjugated secondary goat anti-rabbit (Dianova, Hamburg, Germany) or goat anti-mouse (Biozol, Eching, Germany) antibody, respectively. The reactive bands were visualized employing a chemiluminescent detection kit (ECL Plus, Amersham Pharmacia, Uppsala, Sweden). $\beta$-Actin (Millipore, Billerica, MA) or total Akt (Cell Signaling, Danvers, MA) was used as loading control, respectively. For densitometric quantification of the bands, a special software (LiCor Biosciences, Lincoln, NE) was employed.

Caspase-3-like Activity. Caspase-3 like activity was measured as described previously. ${ }^{16}$ Extracts were incubated with Ac-DEVD-AFC, and the generation of AFC was determined by fluorescence measurement (excitation: $385 \mathrm{~nm}$; emission: $505 \mathrm{~nm}$ ).

Transaminases. Activities of aminotransferases (alanine transferase (ALT) and aspartate transferase (AST)), as well as LDH of the collected perfusate were determined at different time points of the reperfusion period by using a serum multiple analyzer (Olympus AU 2700, Hamburg, Germany) at $37^{\circ} \mathrm{C}$ by the Institute for Clinical Chemistry, Klinikum Grosshadern, University of Munich, Germany.

TNF- $\alpha$ ELISA. Rat TNF- $\alpha$ UltraSensitive ELISA kit was obtained from BioSource. Determination of TNF- $\alpha$ levels of the perfusate was performed according to the manufacturer's manual. The absorbance 
was measured at $450 \mathrm{~nm}$ using the Sunrise absorbance reader from TECAN. Color development was proportional to the amount of rat TNF- $\alpha$ in the perfusate.

Statistical Analysis. The number of experiments is indicated in the respective figure legend. Data are expressed as mean \pm SEM. Statistical analysis was performed using the GraphPad Prism 3.03 software (GraphPad Software Inc., San Diego, CA). Significance (*, \#) was calculated at the $95 \%$ confidence interval between indicated groups, using an unpaired $t$ test.

Acknowledgment. This work was supported by grants of the Deutsche Forschungsgemeinschaft (DFG) FOR 440.

\section{References and Notes}

(1) Das, S.; Das, D. K. Recent Pat. Cardiovasc. Drug Discovery 2007, 2, 133-138

(2) Hertog, M. G.; Feskens, E. J.; Hollman, P. C.; Katan, M. B.; Kromhout, D. Lancet 1993, 342, 1007-1011.

(3) Rahman, I.; Biswas, S. K.; Kirkham, P. A. Biochem. Pharmacol. 2006, 72, 1439-1452.

(4) Bors, W.; Michel, C.; Stettmaier, K. Biofactors 1997, 6, 399-402.

(5) Teixeira, S.; Siquet, C.; Alves, C.; Boal, I.; Marques, M. P.; Borges, F.; Lima, J. L.; Reis, S. Free Radical Biol. Med. 2005, 39, 10991108 .

(6) Gloire, G.; Legrand-Poels, S.; Piette, J. Biochem. Pharmacol. 2006, $72,1493-1505$

(7) Su, J. F.; Guo, C. J.; Wei, J. Y.; Yang, J. J.; Jiang, Y. G.; Li, Y. F. Biomed. Environ. Sci. 2003, 16, 1-8.

(8) Weisel, T.; Baum, M.; Eisenbrand, G.; Dietrich, H.; Will, F.; Stockis, J. P.; Kulling, S.; Rufer, C.; Johannes, C.; Janzowski, C. Biotechnol. J. 2006, 1, 388-397.

(9) Albini, A.; Dell'Eva, R.; Vene, R.; Ferrari, N.; Buhler, D. R.; Noonan, D. M.; Fassina, G. FASEB J. 2006, 20, 527-529.

(10) Dietz, B. M.; Kang, Y. H.; Liu, G.; Eggler, A. L.; Yao, P.; Chadwick, L. R.; Pauli, G. F.; Farnsworth, N. R.; Mesecar, A. D.; van Breemen, R. B.; Bolton, J. L. Chem. Res. Toxicol. 2005, 18, 1296-1305.

(11) Gerhauser, C. Eur. J. Cancer 2005, 41, 1941-1954.

(12) Gerhauser, C.; Alt, A.; Heiss, E.; Gamal-Eldeen, A.; Klimo, K.; Knauft, J.; Neumann, I.; Scherf, H. R.; Frank, N.; Bartsch, H.; Becker, H. Mol. Cancer Ther. 2002, 1, 959-969.

(13) Plazar, J.; Zegura, B.; Lah, T. T.; Filipic, M. Mutat. Res. 2007, 632, $1-8$.

(14) Galaris, D.; Barbouti, A.; Korantzopoulos, P. Curr. Pharm. Des. 2006, $12,2875-2890$.

(15) Bilzer, M.; Gerbes, A. L. J. Hepatol. 2000, 32, 508-515.

(16) Grutzner, U.; Keller, M.; Bach, M.; Kiemer, A. K.; Meissner, H.; Bilzer, M.; Zahler, S.; Gerbes, A. L.; Vollmar, A. M. World J. Gastroenterol. 2006, 12, 1049-1055.

(17) Fan, C.; Zwacka, R. M.; Engelhardt, J. F. J. Mol. Med. 1999, 77, 577-592.

(18) Glantzounis, G. K.; Salacinski, H. J.; Yang, W.; Davidson, B. R.; Seifalian, A. M. Liver Transpl. 2005, 11, 1031-1047.

(19) He, S. Q.; Zhang, Y. H.; Venugopal, S. K.; Dicus, C. W.; Perez, R. V. Ramsamooj, R.; Nantz, M. H.; Zern, M. A.; Wu, J. Liver Transpl. 2006, 12, 1869-1879.

(20) Bilzer, M.; Roggel, F.; Gerbes, A. L. Liver Int. 2006, 26, 1175-1186.
(21) Muller, C.; Dunschede, F.; Koch, E.; Vollmar, A. M.; Kiemer, A. K. Am. J. Physiol. Gastrointest. Liver Physiol. 2003, 285, G769-778.

(22) Hur, G. M.; Ryu, Y. S.; Yun, H. Y.; Jeon, B. H.; Kim, Y. M.; Seok, J. H.; Lee, J. H. Biochem. Biophys. Res. Commun. 1999, 261, 917922.

(23) Zhong, Z.; Froh, M.; Connor, H. D.; Li, X.; Conzelmann, L. O.; Mason, R. P.; Lemasters, J. J.; Thurman, R. G. Am. J. Physiol. Gastrointest. Liver Physiol. 2002, 283, G957-964.

(24) Matsui, N.; Kasajima, K.; Hada, M.; Nagata, T.; Senga, N.; Yasui, Y.; Fukuishi, N.; Akagi, M. J. Toxicol. Sci. 2005, 30, 103-110.

(25) Suetsugu, H.; Iimuro, Y.; Uehara, T.; Nishio, T.; Harada, N.; Yoshida, M.; Hatano, E.; Son, G.; Fujimoto, J.; Yamaoka, Y. Gut 2005, 54, $835-842$.

(26) Lanteri, R.; Acquaviva, R.; Di Giacomo, C.; Sorrenti, V.; Li Destri, G.; Santangelo, M.; Vanella, L.; Di Cataldo, A. Microsurgery 2007, $27,245-251$.

(27) Fiorini, R. N.; Donovan, J. L.; Rodwell, D.; Evans, Z.; Cheng, G.; May, H. D.; Milliken, C. E.; Markowitz, J. S.; Campbell, C.; Haines, J. K.; Schmidt, M. G.; Chavin, K. D. Liver Transpl. 2005, 11, 298308.

(28) Plin, C.; Tillement, J. P.; Berdeaux, A.; Morin, D. Eur. J. Pharmacol. 2005, 528, 162-168.

(29) Tsuda, T.; Horio, F.; Osawa, T. Biofactors 2000, 13, 133-139.

(30) Yuzawa, H.; Fujioka, H.; Mizoe, A.; Azuma, T.; Furui, J.; Nishikawa, M.; Hashida, M.; Kanematsu, T. Hepatogastroenterology 2005, 52, 839-843.

(31) Bilzer, M.; Baron, A.; Schauer, R.; Steib, C.; Ebensberger, S.; Gerbes, A. L. Digestion 2002, 66, 49-57.

(32) Liu, Z. J.; Yan, L. N.; Li, S. W.; You, H. B.; Gong, J. P. Acta Pharmacol. Sin. 2006, 27, 1479-1486.

(33) Mullonkal, C. J.; Toledo-Pereyra, L. H. J. Invest. Surg. 2007, 20, 195203

(34) Duenschede, F.; Erbes, K.; iegler, N.; Ewald, P.; Kircher, A.; Westermann, S.; Schad, A.; Miesmer, I.; Albrecht-Schöck, S.; Gockel, I.; Kiemer, A. K.; Junginger, T. World J. Gastroenterol. 2007, 13, 3692-3698

(35) Jaeschke, H.; Lemasters, J. J. Gastroenterology 2003, 125, 1246-1257.

(36) Colgate, E. C.; Miranda, C. L.; Stevens, J. F.; Bray, T. M.; Ho, E. Cancer Lett. 2007, 246, 201-209.

(37) Harikumar, K. B.; Kunnumakkara, A. B.; Anh, K. S.; Anand, P.; Krishnan, S.; Guha, S.; Aggarwal, B. B. Blood 2009, 113, 2003-2013.

(38) Mueller, T. H.; Kienle, K.; Beham, A.; Geissler, E. K.; Jauch, K. W.; Rentsch, M. Transplantation 2004, 78, 1267-1273.

(39) Franke, T. F.; Hornik, C. P.; Segev, L.; Shostak, G. A.; Sugimoto, C. Oncogene 2003, 22, 8983-8998.

(40) Harada, N.; Hatano, E.; Koizumi, N.; Nitta, T.; Yoshida, M.; Yamamoto, N.; Brenner, D. A.; Yamaoka, Y. J. Surg. Res. 2004, 121, 159-170.

(41) Maeda, S.; Kamata, H.; Luo, J. L.; Leffert, H.; Karin, M. Cell 2005, 121, 977-990.

(42) Kuboki, S.; Okaya, T.; Schuster, R.; Blanchard, J.; Denenberg, A.; Wong, H. R.; Lentsch, A. B. Am. J. Physiol. Gastrointest. Liver Physiol. 2007, 292, G201-207.

(43) Vogel, S.; Ohmayer, S.; Brunner, G.; Heilmann, J. Bioorg. Med. Chem. 2008, 16, 4286-4293.

(44) Bradford, M. M. Anal. Biochem. 1976, 72, 248-254.

(45) Marklund, S.; Marklund, G. Eur. J. Biochem. 1974, 47, 469-474.

NP900230P 